\title{
Parâmetros hematológicos de tilápias-do-Nilo (Oreochromis niloticus) alimentadas com diferentes fontes de óleo
}

\author{
Hematological parameters of Nile tilapia ("Oreochromis niloticus”) fed different oil \\ sources
}

\author{
COSTA, Diego Vicente da ${ }^{1 *}$; FERREIRA, Milena Wolff ${ }^{2}$; NAVARRO, Rodrigo \\ Diana $^{3}$; ROSA, Priscila Vieira ${ }^{1}$; MURGAS, Luis David Solis ${ }^{4}$
}

\begin{abstract}
${ }^{1}$ Universidade Federal de Lavras, Departamento de Zootecnia, Lavras, Minas Gerais, Brasil.
${ }^{2}$ Universidade Católica Dom Bosco, Centro de Ciências Agrárias, Departamento de Zootecnia, Campo Grande, Mato Grosso do Sul, Brasil.

${ }^{3}$ Universidade de Brasília, Faculdade de Agronomia e Medicina Veterinária, Brasília, Distrito Federal, Brasil.

${ }^{4}$ Universidade Federal de Lavras, Departamento de Ciências Veterinárias, Lavras, Minas Gerais, Brasil.

*Endereço para correspondência: diego@zootecnista.com.br
\end{abstract}

\section{RESUMO}

Objetivou-se avaliar a influência das fontes de óleo da dieta sobre os parâmetros hematológicos de tilápias-do-Nilo (Oreochromis niloticus). Foram utilizados 112 juvenis, com peso médio inicial de $50 \pm 12 \mathrm{~g}$, distribuídos em 16 caixas com capacidade total de $100 \mathrm{~L}$ cada, num delineamento inteiramente casualizado com quatro tratamentos e quatro repetições, contendo sete peixes por repetição. Os tratamentos eram constituídos por: tratamento um - óleo de soja; tratamento dois - óleo de peixe; tratamento três - óleo de linhaça; tratamento quatro - óleo de oliva. As rações eram semipurificadas, isoproteicas $(32 \%$ de proteína bruta) e isocalóricas (3200 kcal de energia bruta/kg de ração). Não houve diferença $(P>0,05)$ entre os tratamentos quanto ao número e diferenciação de leucócitos, número de eritrócitos totais e níveis de hemoglobina. Os peixes do tratamento um apresentaram níveis superiores de hematócrito $\quad(\mathrm{P}<0,05) \quad$ comparados aos tratamentos dois e três. Encontrou-se maior volume corpuscular médio (VCM) nos peixes do tratamento quatro em relação aos outros tratamentos $(\mathrm{P}<0,05)$. O tratamento três apresentou concentração de hemoglobina corpuscular média (CHCM) superior, comparado aos peixes do tratamento quatro $(\mathrm{P}<0,05)$. As fontes de ácidos graxos da dieta podem influenciar os parâmetros hematológicos de tilápia-do-Nilo (Oreochromis niloticus). Houve uma tendência de aumento na eritropoiese de tilápia-do-Nilo alimentadas com dietas contendo altos níveis de ácidos graxos da série $\omega-6$. As fontes dietéticas de óleo testadas não foram capazes de alterar o número total de eritrócitos e células sanguíneas da série branca em tilápias-do-Nilo.

Palavras-chave: ácidos graxos, peixe, ração, sangue

\section{SUMMARY}

The aim of this study was to evaluate the influence of dietary lipid sources on Nile tilapia (Oreochromis niloticus) hematological parameters. 112 juveniles of Nile tilapia with average initial weight of $50 \pm 12 \mathrm{~g}$ were distributed in 16 tanks with total capacity of $100 \mathrm{~L}$ each in a totally randomized design with four treatments and four repetitions with seven fish each replicate. Treatments were composed of: treatment one - soybean oil; treatment two fish oil; treatment three - linseed oil; treatment four - olive oil. Experimental diets were semipurified, isonitrogenous (32\% crude protein) and isocaloric (3200 kcal gross energy $/ \mathrm{kg}$ of ration). No difference was found between treatments in hemoglobin rates, number of total erythrocytes and leucocytes differential counting $(\mathrm{P}>0.05)$. Fish from treatment one presented higher hematocrit rates compared with treatment two and treatment three $(\mathrm{P}<0.05)$. The highest level of mean 
corpuscular volume was observed in fish from treatment four $(\mathrm{P}<0.05)$. Fish from treatment three showed higher levels of mean corpuscular hemoglobin concentration compared with treatment four $(\mathrm{P}<0.05)$. Dietary lipid sources can influence the hematological parameters of Nile tilapia (Oreochromis niloticus). It was observed a trend of increased erythropoiesis in Nile tilapia fed diets with high levels of $\omega-6$ series fatty acid. Dietary oils were not able to change the total number of erythrocytes and white blood cells in Nile tilapia.

Keywords: blood, fatty acids, fish, ration

\section{INTRODUÇÃO}

Vários estudos demonstraram a existência de diferenças no desempenho e saúde dos peixes, incluindo a tilápia, em função das diferentes fontes de lipídeos na dieta. (LIM et al., 2011; MOURENTE et al., 2005) O conhecimento da resposta hematológica sob diferentes dietas pode ser uma ferramenta útil para novas formulações, sob a ótica da defesa orgânica do animal, consequentemente a profilaxia de enfermidades.

Os ácidos graxos essenciais são sintetizados de forma limitada pelos peixes, portanto, devem ser fornecidos na dieta para suprir suas exigências nutricionais. Como função dos ácidos graxos essenciais poli-insaturados, podemos citar sua ação sobre o sistema imunológico (MOURENTE et al., 2005), ação anti-inflamatória e precursores de outros ácidos graxos (Andrade \& Carmo, 2006), além de afetar o desempenho produtivo. (LIM et al., 2011)

Estudos sobre o efeito dos lipídios e ácidos graxos adicionados à dieta sobre a resposta imunológica e resistência dos peixes têm sido realizados, porém com resultados contraditórios. (HAN et al.,
2012; LI et al., 2013; MONTERO et al., 2010)

A tilápia-do-Nilo (Oreochromis niloticus) é bastante resistente a doenças, porém, o cultivo intensivo e o crescimento acelerado podem influenciar o status imunológico e aumentar a susceptibilidade a doenças. (MIAN et al., 2009) Em várias espécies de peixes foi evidenciado que as fontes de lipídeos da dieta podem suprimir ou estimular alguns parâmetros imunológicos. Contudo, estudos relacionados à influência dos ácidos graxos dietéticos no sistema imune de tilápias ainda são bastante escassos. (FERREIRA et al., 2011)

Objetivou-se com este trabalho avaliar os efeitos do fornecimento de diferentes fontes de lipídios na dieta sobre os níveis de hematócrito, hemoglobina, eritrócitos, volume corpuscular médio (VCM), concentração de hemoglobina corpuscular média (CHCM) e contagem e diferenciação de leucócitos de tilápiasdo-Nilo (Oreochromis niloticus).

\section{MATERIAL E MÉTODOS}

O experimento foi conduzido na Estação de Piscicultura do Departamento de Zootecnia da Universidade Federal de Lavras (UFLA), Minas Gerais, Brasil, no período de agosto a dezembro de 2010.

Foram utilizados 112 juvenis machos de tilápia-do-Nilo (Oreochromis niloticus), aleatoriamente distribuídos em 16 tanques circulares com capacidade total de 100 litros cada, em um sistema de recirculação de água, com biofiltro, filtro de areia e filtro ultravioleta. $\mathrm{O}$ experimento foi montado em um delineamento inteiramente ao acaso, contendo quatro tratamentos (fontes de óleo na dieta) e quatro repetições (caixas) com sete peixes por unidade experimental. Os peixes foram 
aclimatados às condições laboratoriais por 10 dias antes de receberem as dietas experimentais, totalizando 120 dias de experimento. Os juvenis foram alimentados até a saciedade aparente duas vezes ao dia (8:00 h e 17:00 h), sendo as sobras de rações e fezes sifonadas diariamente. A temperatura e oxigênio dissolvido da água foram medidos diariamente, no mesmo horário do manejo alimentar, com auxílio de um oxímetro (YSI ${ }^{\circledR}$, USA). Amônia e pH foram mensurados semanalmente com um kit comercial (Alcon ${ }^{\circledR}$, Brasil).
As dietas eram semipurificadas, isoproteicas e isoenergéticas, com aproximadamente $32 \%$ de proteína bruta e $3200 \mathrm{Kcal}$ de energia bruta/kg de ração. Foram adicionados $5 \%$ de óleo em cada ração, porém diferiam entre si pela fonte de óleo utilizada, sendo: Tratamento um - óleo de soja; Tratamento dois - óleo de linhaça; Tratamento três - óleo de peixe; Tratamento quatro - óleo de oliva. As formulações das dietas experimentais estão apresentadas na Tabela 1.

Tabela 1. Composição das dietas experimentais

\begin{tabular}{|c|c|c|c|c|}
\hline \multirow{2}{*}{ Ingredientes (\%) } & \multicolumn{4}{|c|}{ Tratamentos } \\
\hline & OS & OL & OP & $\mathrm{OO}$ \\
\hline Dextrina & 49 & 49 & 49 & 49 \\
\hline Albumina & 32,8 & 32,8 & 32,8 & 32,8 \\
\hline Gelatina & 8,3 & 8,3 & 8,3 & 8,3 \\
\hline Celulose & 3,38 & 3,38 & 3,38 & 3,38 \\
\hline Óleo de soja & 5 & - & - & - \\
\hline Óleo de linhaça & - & 5 & - & - \\
\hline Óleo de peixe & - & - & 5 & - \\
\hline Óleo de oliva & - & - & - & 5 \\
\hline Fosfato Bicálcico & 1 & 1 & 1 & 1 \\
\hline Mistura Vitamínica $^{1}$ & 0,33 & 0,33 & 0,33 & 0,33 \\
\hline Mistura Mineral $^{2}$ & 0,17 & 0,17 & 0,17 & 0,17 \\
\hline Antioxidante (BHT) & 0,02 & 0,02 & 0,02 & 0,02 \\
\hline Proteína bruta (\%) & 32.16 & 33.05 & 32.18 & 32.20 \\
\hline Energia bruta $\left(\mathrm{kcal}^{\mathrm{kg}} \mathrm{kg}^{-1}\right)$ & 4059.46 & 3998.78 & 4028.90 & 4046.13 \\
\hline Extrato etéreo $(\%)$ & 5.86 & 5.10 & 5.48 & 5.16 \\
\hline Umidade $(\%)$ & 3.37 & 3.05 & 3.20 & 3.56 \\
\hline
\end{tabular}

OS - óleo de soja; OL - óleo de linhaça; OP - óleo de peixe; OO - óleo de oliva.

${ }^{1}$ Mistura Vitamínica, composição (quantidade/kg): vitamina A 1500 U.I.; vitamina B2, 15mg; vitamina B3, 1000 U.I.; vitamina B12, 1000 U.I.; vitamina E, 25mg; vitamina PP, 120mg; colina, 2000mg; pantotenato de cálcio, $80 \mathrm{mg}$; ácido fólico, 2mg e BHT, 170mg.

${ }^{2}$ Mistura Mineral, composição (quantidade/kg): Manganês 80mg; Ferro, 24mg; Zinco, 50mg; Cobre, $8 \mathrm{mg}$; Iodo, $3 \mathrm{mg}$ e Selênio, $0,10 \mathrm{mg}$.

Após o término do fornecimento das dietas experimentais, os peixes foram mantidos em jejum por $24 \mathrm{~h}$ e foram sedados com benzocaína na concentração de 200mg/L. Após os peixes perderem o equilíbrio no perfil da água e terem o movimento opercular reduzido, foram pesados e mensurados o comprimento corporal total e comprimento padrão (medida entre a extremidade anterior da cabeça e a inserção da nadadeira caudal). Foram coletadas amostras de 
sangue por punção cardíaca com auxílio de seringas estéreis contendo EDTA (ácido etilenodiaminotetracético) na concentração de $10 \%$. Ao fim da coleta de sangue, os peixes eram devolvidos aos aquários com benzocaína para serem eutanasiados, ao observar a parada completa dos movimentos operculares. As análises hematológicas foram realizadas no Laboratório de Fisiologia do Departamento de Medicina Veterinária e Laboratório de Nutrição Animal do Departamento de Zootecnia da UFLA. Foram preparadas extensões sanguíneas coradas pelo método de Rosenfeld (1974), para contagem e diferenciação de leucócitos. Dentre o total dos leucócitos, foram diferenciados os trombócitos, linfócitos, neutrófilos, monócitos, basófilos, eosinófilos e células granulocíticas especiais (CGE). A contagem foi realizada com o auxílio de microscópio óptico com objetiva no aumento de 1000 vezes, sendo realizada a contagem diferencial de 50 células na parte superior e 50 na parte inferior, da metade para o fim da borda da extensão. Dentre as células da série vermelha, foi realizada a contagem total de eritrócitos em câmara de Neubauer; quantificação da hemoglobina, segundo Collier (1944) e volume corpuscular médio (VCM) e concentração de hemoglobina corpuscular média (CHCM), segundo metodologia proposta por Wintrobe (1934). Para a determinação do hematócrito foi utilizada a técnica de microhematócrito, de acordo com Goldenfarb et al. (1971).

A determinação do perfil cromatográfico das rações (Tabela 2) foi realizada no Departamento de Química da UFLA.

Tabela 2. Composição de ácidos graxos das dietas experimentais elaboradas com diferentes fontes de óleo

\begin{tabular}{|c|c|c|c|c|}
\hline \multirow{2}{*}{ Ácidos graxos (\%) } & \multicolumn{4}{|c|}{ Dietas } \\
\hline & OS & $\mathrm{OL}$ & OP & $\mathrm{OO}$ \\
\hline C 16:0 & 16.07 & 12.73 & 20.38 & 18.65 \\
\hline C $16: 1 \omega-7$ & 0.02 & 0.04 & 0.01 & 4.88 \\
\hline C 18:0 & 19.78 & 18.85 & 15.27 & 26.55 \\
\hline C $18: 1 \omega-9$ & 9.90 & 9.29 & 6.06 & 18.35 \\
\hline C $18: 2 \omega-6$ & 35.06 & 17.13 & 11.26 & 12.41 \\
\hline C $18: 3 \omega-3$ & 6.57 & 31.34 & 8.70 & 0.73 \\
\hline С $20: 1 \omega-9$ & 0.60 & 0.41 & 3.15 & 4.32 \\
\hline С $20: 2 \omega-6$ & 0.15 & 0.06 & 0.80 & 1.29 \\
\hline С $20: 3 \omega-6$ & 1.10 & 0.01 & 0.31 & 1.38 \\
\hline С $20: 4 \omega-6$ & 6.23 & 0.04 & 0.85 & 3.40 \\
\hline С $20: 5 \omega-3$ & 0.06 & 1.09 & 7.49 & 1.46 \\
\hline C $22: 6 \omega-3$ & 0.19 & 2.92 & 10.98 & 1.59 \\
\hline \multicolumn{5}{|l|}{ Total } \\
\hline$\omega-3$ & 6.82 & 35.35 & 27.17 & 3.78 \\
\hline$\omega-6$ & 42.54 & 17.24 & 13.22 & 18.48 \\
\hline$\omega-9$ & 10.50 & 9.70 & 9.21 & 21.67 \\
\hline Saturados & 35.85 & 31.58 & 40.65 & 45.20 \\
\hline Monoinsaturados & 10.52 & 9.74 & 9.22 & 24.55 \\
\hline Poli-insaturados & 42.36 & 52.59 & 40.39 & 24.26 \\
\hline$\omega-3 / \omega-6$ & 0.19 & 2.05 & 1.68 & 0.20 \\
\hline
\end{tabular}

$\mathrm{OS}=$ óleo de soja, $\mathrm{OL}=$ óleo de linhaça, $\mathrm{OP}=$ óleo de peixe, $\mathrm{OO}=$ óleo de oliva. 
A extração dos lipídios da dieta seguiu a metodologia proposta por Folch et al. (1957). Posteriormente, as amostras foram transmetiladas de acordo com o método de Hartman \& Lago (1973), o qual consiste na saponificação e conversão dos ácidos graxos livres em ésteres metílicos. Tais ésteres metílicos de ácidos graxos foram submetidos à cromatografia gasosa, usando $\mathrm{O}$ equipamento Varian 3800, dotado com detector em chamas, técnica de injeção em "splintless", coluna capilar de sílica fundida DB-WAX $(30 \mathrm{~m}$ x $0.25 \mathrm{~mm} \times$ $0.25 \mu \mathrm{m})$, acoplado a um software (Borwin, JMBS, Développements). O programa de temperatura adotado foi de $75-235^{\circ} \mathrm{C}$ a $10^{\circ} \mathrm{C} \mathrm{min}^{-1}$. O gás de arraste foi o nitrogênio em um fluxo constante de $2 \mathrm{~mL} \mathrm{~min}^{-1}$. Cada um dos ácidos graxos foi identificado em relação a um padrão externo conhecido (Supelco, 37 da mistura FAME).

As pressuposições para a análise de variância foram validadas pelos testes Bartlett para homogeneidade da variância e Shapiro-Wilk para distribuição normal dos resíduos. Os dados foram analisados através de análise da variância utilizando $\mathrm{o}$ software SAS (SAS INSTITUTE, 1999), sendo as médias comparadas pelo teste SNK com 5\% de significância.

\section{RESULTADOS E DISCUSSÃO}

Durante o experimento, os valores médios de temperatura e oxigênio dissolvido da água oscilaram entre $26,52 \pm 1,83^{\circ} \mathrm{C}$ e $4,37 \pm 1,05 \mathrm{mg} / \mathrm{L}$, respectivamente. $\mathrm{O} \mathrm{pH}$ variou entre $7,00 \pm 0,02$ e amônia entre $0,03 \pm$ $0,001 \mathrm{mg} / \mathrm{L}$, estando esses valores dentro do aceitável para o cultivo da espécie em questão. (RIDHA \& CRUZ, 2001)

Não houve diferenças significativas entre os tratamentos $(\mathrm{P}>0,05)$ para peso inicial, peso final e variáveis morfométricas (Tabela 3 ). Os resultados sugerem que nenhuma das fontes de óleo testadas foi impalatável ou rejeitada pelos peixes, haja vista que os tratamentos apresentaram pesos finais e crescimento total e padrão similares. Higuchi et al. (2012) não observaram diferenças significativas nas variáveis de desempenho produtivo de tilápiasdo-Nilo alimentadas com dietas contendo diferentes fontes lipídicas. Vargas et al. (2007), avaliando óleo de linhaça, óleo de peixe e óleo de milho na dieta de tilápias-do-Nilo, também não encontraram diferenças significativas nos parâmetros de desempenho avaliados.

Tabela 3. Peso inicial, peso final e variáveis morfométricas de tilápias-do-Nilo (Oreochromis niloticus) alimentadas com diferentes fontes de óleo

\begin{tabular}{lcccc}
\hline Tratamento & Peso inicial $(\mathrm{g})^{1}$ & ${\text { Peso final }(\mathrm{g})^{1}}^{1}$ & CRESCT $(\mathrm{cm})^{1}$ & ${\text { CRESCP }(\mathrm{cm})^{1}}^{1}$ \\
\hline Óleo de soja & $49,31 \pm 7,21$ & $229,50 \pm 28,45$ & $6,96 \pm 1,87$ & $5,88 \pm 1,24$ \\
Óleo de linhaça & $53,77 \pm 8,6$ & $213,88 \pm 35,31$ & $6,72 \pm 1,13$ & $5,64 \pm 1,36$ \\
Óleo de peixe & $47,51 \pm 7,8$ & $206,25 \pm 18,93$ & $6,32 \pm 1,11$ & $4,45 \pm 1,44$ \\
Óleo de oliva & $52,88 \pm 9,33$ & $218,63 \pm 21,62$ & $6,21 \pm 1,90$ & $4,64 \pm 1,26$ \\
\hline
\end{tabular}

CRESCT $=$ crescimento total, CRESCP $=$ crescimento padrão.

Resultados apresentados como média \pm desvio padrão $(\mathrm{n}=28)$.

${ }^{1}$ Não significativo $(\mathrm{P}>0,05)$ de acordo com teste SNK. 
Foram observadas diferenças $(\mathrm{P}<0,05)$ entre os tratamentos para os valores de hematócrito, VCM e CHCM. Não houve diferença $(\mathrm{P}>0,05)$ entre os tratamentos para os níveis de hemoglobina e número de eritrócitos totais (Tabela 4). Não houve diferença entre os tratamentos $(\mathrm{P}>0,05)$ para os percentuais médios e diferenciação de leucócitos (Tabela 5).

Tabela 4. Níveis de hematócrito, volume corpuscular médio (VCM) e concentração de hemoglobina corpuscular média (CHCM), hemoglobina e eritrócitos de tilápias-do-Nilo (Oreochromis niloticus) alimentadas com diferentes fontes de óleo

\begin{tabular}{lccccc}
\hline Tratamento & $\begin{array}{c}\text { Hematócrito } \\
(\%)\end{array}$ & $\operatorname{VCM}(\mu 3)$ & CHCM $(\%)$ & $\begin{array}{c}\text { Hemoglobina } \\
(\mathrm{g} / \mathrm{dL})\end{array}$ & $\begin{array}{c}\text { Eritrócitos } \\
\left(10^{6} / \mathrm{mm}^{3}\right)\end{array}$ \\
\hline $\begin{array}{l}\text { Óleo de soja } \\
\text { Óleo de }\end{array}$ & $32,4 \pm 6,5^{\mathrm{a}}$ & $534,78 \pm 121,92^{\mathrm{b}}$ & $59,78 \pm 22,91^{\mathrm{ab}}$ & $16,87 \pm 4,95^{\mathrm{a}}$ & $5,42 \pm 2,33^{\mathrm{a}}$ \\
$\begin{array}{l}\text { linhaça } \\
\text { Óleo de } \\
\text { peixe }\end{array}$ & $23,0 \pm 4,4^{\mathrm{b}}$ & $528,64 \pm 286,43^{\mathrm{b}}$ & $73,23 \pm 21,24^{\mathrm{ab}}$ & $16,97 \pm 4,13^{\mathrm{a}}$ & $5,01 \pm 1,93^{\mathrm{a}}$ \\
$\begin{array}{l}\text { Óleo de } \\
\text { oliva }\end{array}$ & $20,4 \pm 7,5^{\mathrm{b}}$ & $468,90 \pm 216,03^{\mathrm{b}}$ & $78,43 \pm 25,02^{\mathrm{a}}$ & $14,90 \pm 3,44^{\mathrm{a}}$ & $4,72 \pm 1,82^{\mathrm{a}}$ \\
\hline
\end{tabular}

Resultados apresentados como média \pm desvio padrão $(\mathrm{n}=28)$.

Médias seguidas de letras diferentes na mesma coluna diferem entre si $(\mathrm{P}<0,05)$ pelo teste $\mathrm{SNK}$.

Tabela 5. Valores percentuais médios e diferenciação de leucócitos de tilápias-do-Nilo (Oreochromis niloticus) alimentadas com diferentes fontes de óleo

\begin{tabular}{lccccccc}
\hline \multirow{2}{*}{ Tratamento } & \multicolumn{7}{c}{ Tipos dos leucócitos $^{(\mathrm{NS})}$} \\
\cline { 2 - 7 } & Basófilos & CGE & Eosinófilos & Trombócitos & Monócitos & Neutrófilos & Linfócitos \\
\hline $\begin{array}{l}\text { Óleo de soja } \\
\text { Óleo de }\end{array}$ & 0,0 & 0,0 & 0,0 & 26,6 & 1,3 & 3,9 & 68,2 \\
$\begin{array}{l}\text { linhaça } \\
\text { Óleo de }\end{array}$ & 0,0 & 0,0 & 0,0 & 20,3 & 0,6 & 6,8 & 72,3 \\
peixe & 0,0 & 0,0 & 0,0 & 26,2 & 0,3 & 4,8 & 68,7 \\
Óleo de oliva & 0,0 & 0,0 & 0,0 & 23,1 & 0,5 & 6,6 & 69,8 \\
\hline
\end{tabular}

$\mathrm{CGE}=$ Células granulocíticas especiais.

${ }^{(N S)}$ Não significativo $(\mathrm{P}>0,05)$ de acordo com teste SNK.

Os peixes alimentados com as dietas formuladas com óleo de soja, que contém altos níveis de ácidos graxos da série $\omega-6$, apresentaram maiores níveis de hematócrito em relação aos animais alimentados com as dietas formuladas com óleo de linhaça e óleo de peixe $(\mathrm{P}<0,05)$. Resultado semelhante foi encontrado por Ferreira et al. (2011), que observaram valores maiores de hematócrito em tilápias-do-Nilo alimentadas com óleo de soja, quando comparado aos peixes alimentados com óleo de linhaça, óleo de peixe e óleo de oliva. No entanto, híbridos de tilápia ( $O$. niloticus $\times O$. aureus) alimentados com dietas contendo diferentes níveis de ácido linolênico $\omega$-3 e ácido linoleico $\omega$ 6 não apresentaram diferenças significativas nos valores de hematócrito. (Li et al., 2013) Mourente et al. (2005) não observaram diferença significativa 
na porcentagem de hematócrito em robalo europeu Dicentrarchus labrax alimentados com óleo de linhaça, colza, peixe e oliva. A diferença entre os resultados dos trabalhos supracitados pode estar relacionada à variação nas condições experimentais, espécies estudadas, hábitos alimentares e tamanho dos peixes, perfil de ácidos graxos e qualidade dos óleos utilizados na composição das dietas. A influência dos ácidos graxos dietéticos na porcentagem de hematócrito e eritropoiese de peixes ainda necessita ser elucidada.

Foi observado maior VCM nos peixes alimentados com as dietas de óleo de oliva em relação aos demais tratamentos $(\mathrm{P}<0,05)$. Já os peixes alimentados com as dietas contendo óleo de peixe apresentaram níveis superiores de CHCM comparados com aqueles alimentados com a dieta de óleo de oliva $(\mathrm{P}<0,05)$. Apesar da grande variação, os valores de CHCM e VCM foram em média maiores quando comparados aos encontrados por Tavares-Dias \& Moraes (2003) para tilapia rendalli e por Ranzani-Paiva et al. (1999) para curimbatá (Prochilodus scrofa), pacu (Piaractus mesopotamicus) e tambaqui (Colossoma macropomum).

Os valores médios de hemoglobina apresentados neste estudo estão de acordo com os valores encontrados por Ranzani-Paiva et al. (2000) para piava (Schizodon borellii) e curimbatá (Prochilodus lineatus), Bittencourt et al. (2003) para tilápias-do-Nilo e TavaresDias et al. (1999) para pacu (Piaractus mesopotamicus). No presente estudo, o fato de os peixes alimentados com as dietas formuladas com óleo de oliva apresentarem menor concentração de hemoglobina, aliado ao alto volume corpuscular, levou à menor concentração de hemoglobina corpuscular média, quando comparado aos demais. As diferenças observadas nesses parâmetros podem ter ocorridas devido à variação do perfil de ácidos graxos nas células vermelhas, as quais podem alterar as propriedades da membrana tal como a resistência osmótica. (Hagve et al., 1991) Além disso, Ranzani-Paiva (1999) relata que a concentração de hemoglobina e CHCM variam inter e intraespécie e tais variações podem ser atribuídas a fatores exógenos, como a temperatura, concentração de oxigênio dissolvido na água, ciclo sazonal, estresse e fatores endógenos, tais como sexo, estádio de maturação gonadal, estado nutricional e doenças. A dieta contendo óleo de oliva apresentou alto teor de ácidos graxos da série $\omega-9$ e baixo teor de ácidos graxos da série $\omega-3$ e $\omega-6$. De acordo com Erdal et al. (1991), que ao estudarem a relação entre a inclusão de vários níveis de vitamina $\mathrm{C}$ e ácidos graxos $\omega-3$ em dietas de salmão do Atlântico, observaram que os ácidos graxos da série w-3 diminuem a fragilidade dos eritrócitos. Por conseguinte, a dieta de óleo de oliva promoveu um aumento do VCM e diminuição do CHCM, possivelmente devido à menor resistência osmótica proporcionada pelo perfil de ácidos graxos da dieta, já que o aumento do VCM pode representar alterações eletrolíticas e influxo de água na célula.

Corroborando com o presente estudo, $\mathrm{Li}$ et al. (2013), avaliando a influência dos ácidos linolênico $\omega$-3 e linoleico $\omega$-6 na dieta de híbrido de tilápia $(O$. niloticus $\times$ $O$. aureus), não encontraram diferenças significativas na contagem total de eritrócitos. Negrete et al. (2009) relata que a diferença no número de eritrócitos totais entre as espécies relatadas na literatura pode estar relacionada com os hábitos e as características fisiológicas, dependentes do ambiente no qual o peixe vive. Os valores da contagem de eritrócitos no presente estudo estão de acordo com os valores encontrados para 
tilápia-do-Nilo (BITTENCOURT et al., 2003), piava Schizodon borellii e curimbatá Prochilodus lineatus (Ranzani-Paiva et al., 2000) e pacu Piaractus mesopotamicus (TAVARESDIAS et al., 1999).

Li et al. (2013), avaliando a influência dos ácidos linolênico $\omega$-3 e linoleico $\omega$-6 na dieta de híbrido de tilápia $(O$. niloticus $\times O$. aureus), não encontraram diferenças significativas na contagem total de leucócitos. Mourente et al. (2005) observaram diminuição significativa no número de leucócitos circulantes e na atividade respiratória dos macrófagos em European seabass (Dicentrarchus labrax L.) alimentados com óleo vegetal (linhaça, oliva e girassol) em comparação aos que receberam dieta contendo óleo de peixe. Os mecanismos pelos quais os ácidos graxos presentes na dieta de peixes atuam sobre a resposta de defesa são atribuídos, em parte, à composição lipídica da membrana e suas propriedades físicas, já que algumas respostas de defesa são baseadas na interação das membranas dos leucócitos, pela ativação da produção de citocinas e também pela influência da produção da prostaglandina e leucotrienos pelos macrófagos. (BALFRY et al., 2006) Os valores de leucócitos totais em teleósteos podem apresentar variações intraespecíficas influenciadas por características próprias de cada indivíduo, em resposta aos estímulos ambientais (NEGRETE et al., 2009) e interespecífica como sazonalidade, reprodução, hábito alimentar, necessidades metabólicas de cada espécie e presença de patógenos (TAVARES-DIAS \& MORAES, 2003; MARTINS et al., 2008). De acordo com Ranzani-Paiva \& Godinho (1986), em Prochilodus scrofa, basófilos ocorrem somente durante a maturação gonadal e eosinófilos não ocorrem em nenhum dos estádios de desenvolvimento. Por conseguinte, não houve ocorrência de basófilos, eosinófilos e células granulocíticas especiais nas extensões sanguíneas do presente estudo. $\mathrm{O}$ fato de não se observar estas células nos esfregaços sanguíneos do presente estudo, pode ser explicado pela idade dos juvenis utilizados no experimento, sendo que a maturação sexual ainda não havia ocorrido.

As fontes de ácidos graxos da dieta podem influenciar os parâmetros hematológicos de tilápia-do-Nilo (Oreochromis niloticus). Houve uma tendência de aumento na eritropoiese em tilápias-do-Nilo alimentadas com dietas contendo altos níveis de ácidos graxos da série $\omega-6$. As fontes dietéticas de óleo testadas não foram capazes de alterar o número total de células sanguíneas da série branca e vermelha em tilápias-doNilo.

\section{REFERÊNCIAS}

ANDRADE, P.M.M.; CARMO, M.G.T. Ácidos graxos n-3: um link entre eicosanóides, inflamação e imunidade.

Revista de Metabolismo e Nutrição, v.8, n.3, p.135-143, 2006.

BALFRY, S.K.; OAKES, J.; ROWSHANDELI, M.; DEACON, G.; SKURA, B.; HIGGS, D.A. Efficacy of an equal blend of canola oil and poultry fat as an alternate dietary lipid source for Atlantic salmon (Salmo salar L.) in seawater. II: effects on haematology and immunecompetence. Aquaculture

Research, v.37, p.192-199, 2006.

BITTENCOURT, N.L.R.; MOLINARI, L.M.; SCOARIS, D.D.O.; PEDROSO, R.B.; NAKAMURA, C.V.; NAKAMURA, T.U.; FILHO, B.A.A; DIAS FILHO, B.P. Hematological and 
Rev. Bras. Saúde Prod. Anim., Salvador, v.15, n.3, p.754-764 jul./set., 2014 http://www.rbspa.ufba.br ISSN 15199940

biochemical values for Nile tilapia $O$. niloticus cultured in semi-intensive system. Acta Scientiarum, v.25, p.385389, 2003.

COLLIER, H.B. The standardizations of blood haemoglobin determinations. Canadian Medical Association Journal, v.50, p.550-552, 1944.

ERDAL, J.J.; EVENSEN, O.; KAURSTAD, O.K.; LILLEHAUG. A.; SOLBAKKEN, R.; THORUD, K. Relationship between diet and immune response in Atlantic salmon (Salmon salar L.) after feeeding various levels of ascorbic acid and omega-3 fatty acids. Aquaculture, v. 98, p.363-379, 1991.

FERREIRA, M.W.; ARAUJO, F.G.; COSTA, D.V.; ROSA, P.V.; FIGUEIREDO, H.C.P.; MURGAS, L.D.S. Influence of Dietary Oil Sources on Muscle Composition and Plasma Lipoprotein Concentrations in Nile Tilapia, Oreochromis niloticus. Journal of the World Aquaculture Society, v.42, n.1, p.24-33, 2011.

FOLCH, J.; LEES, M.; SLOANE; STANLEY, G.H. A simple method for the isolation and purification of total lipides from animal tissues. Journal of Biological Chemistry, v.226, n.1, p.497-509, 1957.

GOLDENFARB, P.B.; BOWIER, F.P.; HALL, E.; BROSIOUS, E.

Reproducibility in the hematology laboratory: the microhematocrit determination. American Journal of Clinical Pathology, v.56, n.1, p.35-9, 1971.

HAGVE, T.A.; JOHANSEN, Y.; CHRISTOPHERSEN, B. The effect of n-3 fatty acids on osmotic fragility of rat erythrocytes. Biochim Biophys Acta, v.1084, n.3, p.251-254, 1991.
HAN, Y.Z.; REN, T.J.; JIANG, Z.Q.; JIANG, B.Q.; GAO, J.; KOSHIO, S.; KOMILUS, C.F. Effects of palm oil blended with oxidized fish oil on growth performances, hematology, and several immune parameters in juvenile Japanese sea bass, Lateolabrax japonicas. Fish Physiology and Biochemistry, v.38, p.1785-1794, 2012.

HARTMAN, L; LAGO, R.C. Rapid preparation of fatty acid methyl esters from lipids. Laboratory Pratice, v.22, p.475-476, 1973.

HIGUCHI, L.H; FEIDEN, A.; KLEIN, S; LUCHESI, J.D.; SCHWERTNER, V.; BITTENCOURT, F.; BOSCOLO, W.R. Desempenho de alevinos de tilápia-donilo alimentados com dietas contendo diferentes óleos vegetais. Revista brasileira de Ciências Veterinárias, v.19, n.3, p.167-171, 2012.

LI, E.; LIM, C.; KLESIUS, P.H.; WELKER, T.L. Growth, Body Fatty Acid Composition, Immune Response, and Resistance to Streptococcus iniae of Hybrid Tilapia, Oreochromis niloticus $\times$ Oreochromis aureus, Fed Diets Containing Various Levels of Linoleic and Linolenic Acids. Journal of the World Aquaculture Society, v.44, n.1, p.42-55, 2013.

LIM, C.; YILDIRIM-AKSOY, M.; KLESIUS, P. Lipid and fatty acid requirements of tilapia. North American Journal of Aquaculture, v.73, p.188193, 2011.

MARTINS, M.L.; MIYAZAKI, D.M.Y.; MORAES, F.R.; GHIRALDELLI, L; ADAMANTE, W.B.; MOURIÑO, J.L.P. Ração suplementada com vitaminas C e E influencia a resposta inflamatória aguda em tilápia do Nilo. Ciência Rural, v.38, p.213-218, 2008. 
MIAN, G.F.; GODOY, D.T.; LEAL, C.A.G.; YUHARA, T.Y.; COSTA, G.M.; FIGUEIREDO, H.C.P. Aspects of the natural history and virulence of $S$. agalactiae infection in Nile tilapia. Veterinary Microbiology, v.136, p.180-183, 2009.

MONTERO, D.; MATHLOUTHI, F.; TORT, L.; AFONSO, J.M.; TORRECILLAS, S.; FERNÁNDEZVAQUERO, A.; NEGRIN, D.; IZQUIERDO, M.S. Replacement of dietary fish oil by vegetable oils affects humoral immunity and expression of pro-inflammatory cytokines genes in gilthead sea bream Sparus aurata. Fish and Shellfish Immunology, v.29, p.1073-1081, 2010.

MOURENTE, G.; GOOD, J.E.; BELL, J.G. Partial substitution of fish oil with rapeseed, linseed and olive oils in diets for European sea bass (Dicentrarchus labrax L.): effects on flesh fatty acid composition, plasma prostaglandins E2 and $F 2 \alpha$, immune function and effectiveness of a fish oil finishing diet. Aquaculture Nutrition, v.11, n.1, p.2540, 2005.

NEGRETE, J.C.C.; CORREA, A.A.G.; GUEVARA, M.J.P.; ATENCIO GARCÍA, V.J.; CARRASCO, S.C.P. Caracterización de células sanguíneas y parámetros hematológicos en blanquillo Sorubim cuspicaudus. Zootecnia Tropical, v.27, n.4, p.393-405, 2009.

RANZANI-PAIVA, M.J.T.; GODINHO, H.M. Hematological characteristics of the curimbatá Prochilodus scrofa Steindacher 1881, stocked in experimental conditions.

Boletim do Instituto de Pesca, v.13, p.115-120, 1986.
RANZANI-PAIVA, M.J.T.; SALLES, A.F.; EIRAS, J.C.; EIRAS, A.C.; ISHIKAWA, C.M.; ALEXANDRINO, A.C. Análises hematológicas de curimbatá (Prochilodus scrofa), pacu (Piaractus mesopotamicus) e tambaqui (Colossoma macropomum) das estações de piscicultura do Instituto de Pesca, estado de São Paulo. Boletim do Instituto de Pesca, v.25, p.77-83, 1999.

RANZANI-PAIVA, M.J.T.; SOUZA, A.T.S.; PAVANELLI, G.C.; TAKEMOTO, R.M.; EIRAS, A.C. Hematological evaluation in commercial fish species from the floodplain if the upper Paraná River, Brazil. Acta Scientiarum, v.2, p.507513, 2000.

RIDHA, M.T.; CRUZ, E.M. Effect of biofilter media on water quality and biological performance of the Nile tilapia Oreochromis niloticus L. reared in a simple recirculating system.

Aquacultural Engineering, v.24, p.157-166, 2001.

ROSENFELD, G. Corante pancrômico para hematologia e citologia clínica: Nova combinação dos componentes May-Grunwald e do Giemsa num só corante de emprego rápido. Memórias do Instituto Butantan, v.20, p. 29-334, 1947.

SAS INSTITUTE. Procedure guide for personal computers. 5. ed. Cary, 1999. $334 \mathrm{p}$.

TAVARES-DIAS, M.; TENANI, R.A.; GIOLI, L.D. Características hematológicas de teleósteos brasileiros. II: Parâmetros sangüíneos do Piaractus mesopotamicus Holmberg, 1887 (Osteichthyes: Characidae) em policultivo intensivo. Revista Brasileira de Zoologia, v.16, p.423431, 1999. 
Rev. Bras. Saúde Prod. Anim., Salvador, v.15, n.3, p.754-764 jul./set., 2014 http://www.rbspa.ufba.br ISSN 15199940

TAVARES-DIAS, M.; MORAES, F.R. Características hematológicas da tilápia rendalli Boulenger, 1986 (osteichthyes: cichlidae) capturada em "pesque-pague" de Franca, São Paulo, Brasil.

Bioscience Journal, v.19, p.107-114, 2003.

VARGAS, R.; SOUZA, S.; TOGNON, F.; GOMES, M.; KESSLER, A.

Desempenho de alevinos de tilápias do nilo (Oreochromis niloticus), alimentados com dietas contendo diferentes fontes de lipídios. Revista Brasileira de Agrociência, v.13, n.3, p.377-381, 2007.

WINTROBE, M.M. Variations in the size and hemoglobin content of erythrocytes in the blood of various vertebrates. Folia Hematologica, v.51, p.32-49, 1934.

Data de recebimento: 14/11/2013

Data de aprovação: 15/07/2014 